\title{
KOMPETENSI, KOMPENSASI DAN MOTIVASI PENGARUHNYA TERHADAP KINERJA TENAGA KESEHATAN \\ (Studi Pada Perawat PNS Ruang Inap Rumah Sakit Umum Daerah dr. H. Moch Ansari Saleh Banjarmasin)
}

\author{
Eka Fakhrun Novianty ${ }^{1)}$, \\ E-mail: ekanovianty93@gmail.com \\ Basuki²), \\ Kurniaty ${ }^{3)}$
}

Magister Manajemen Universitas Islam Kalimantan MAB Banjarmasin

\begin{abstract}
The hospital was formed to serve consumers in the health sector. To achieve success, a strong foundation is needed, namely an organization that is able to strengthen and maximize the performance of its employees. The performance of health workers is the most important part in a hospital, because it can determine the progress or withdrawal of a hospital.

This study aims to test and analyze the effect of competence, compensation and motivation on the performance of Health Workers at the Regional Public Hospital dr. H. Moch Ansari Saleh Banjarmasin with a sample of 50 Civil Servant Nurse Inpatient. The analysis uses multiple regression.

The results of the study prove that partially the competence has a positive and significant effect on the performance of health workers ( $t$ count 3.044, $\alpha$ 0.004). Compensation has a positive but not significant effect ( $t$ count 0.498, $\alpha$ 0.621). Motivation has a positive and significant effect ( $t$ count 3.342, $\alpha$ 0.001). Simultaneously Competence, Compensation, and Motivation Improve the Performance of Health Workers at the Regional Public Hospital dr. H. Moch. Ansari Saleh Banjarmasin. Competence, Compensation, and Motivation affect the Performance of Health Workers at the Regional Public Hospital dr. H. Moch. Ansari Saleh Banjarmasin with an $\mathrm{F}$ count $(8,711)>$ from an $\mathrm{F}$ table $(2.80)$ and a significance value of $0,000<0.05$
\end{abstract}

Keywords: Competence; Compensation; Motivation; Performance 


\section{PENDAHULUAN}

Undang-undang No.36 tahun 2014 pasal 1 ayat 1 menyebutkan bahwa Tenaga Kesehatan adalah setiap orang yang mengabdikan diri dalam bidang kesehatan serta memiliki pengetahuan dan/atau keterampilan melalui pendidikan di bidang kesehatan yang untuk jenis tertentu memerlukan wewenang untuk melakukan upaya kesehatan.

Rumah Sakit dibentuk untuk melayani konsumen dalam bidang kesehatan. Untuk mencapai suatu keberhasilan, diperlukan adanya landasan yang kuat yakni organisasi yang mampu memperkuat dan memaksimumkan kinerja karyawannya.

Rumah Sakit Umum Daerah Dr. H. Moch Ansari Saleh Banjarmasin adalah Rumah Sakit Umum Daerah yang menampung rujukan dari beberapa Rumah sakit dan Puskesmas yang telah ditentukan. Tidak hanya itu, Rumah Sakit Umum Daerah Dr. H. Moch Ansari Saleh Banjarmasin adalah salah satu Rumah Sakit milik Pemerintah terbesar kedua di Banjarmasin. Selain menjadi Rumah Sakit rujukan untuk 3 Kabupaten/kota yaitu kota Banjarmasin, Kabupaten Barito Kuala dan Kota Banjarbaru, Rumah Sakit Umum Daerah Dr. H. Moch Ansari Saleh Banjarmasin juga memberikan berbagai macam pelayanan kesehatan.

Kinerja tenaga kesehatan merupakan aspek penting dalam rumah sakit, karena hal inilah yang akan Kinerja tenaga kesehatan adalah bagian paling penting dalam rumah sakit, karena dapat menentukan maju atau mundurnya sebuah rumah sakit. Berdasarkan uraian diatas, salah satu elemen penting dalam sebuah perusahaan adalah aspek sumber daya manusia. Hal ini disebabkan karena manusia adalah faktor yang paling penting berperan dalam sebuah organisasi/perusahaan. Apabila para tenaga kesehatan berkinerja buruk maka yang terjadi adalah menurunnya kualitas pelayanan yang diberikan dan akan berakibat pada citra rumah sakit menjadi buruk, dan kinerja 
menjadi tolak ukur keberhasilan pelayanan kesehatan yang menunjukkan akuntabilitas lembaga pelayanan dalam kerangka tata pemerintahan yang baik.

Kompetensi merupakan hal paling utama yang harus dimiliki oleh karyawan dalam melaksanakan pekerjaannya, sehingga dengan adanya kompetensi yang telah dimiliki dapat membantu para karyawan di dalam menyelesaikan pekerjaan sesuai dengan target yang telah ditentukan. Kompetensi menjelaskan apa yang dilakukan pegawai di tempat kerja pada berbagai tingkatan dan memperinci standar masingmasing tingkatan, mengidentifikasi karakteristik pengetahuan dan keterampilan yang diperlukan individual yang memungkinkan menjalankan tugas dan tanggung jawab secara efektif sehingga mencapai standar kualitas profesional dalam bekerja dan menghasilkan kinerja yang baik (Wibowo, 2009).

Pengalaman kerja dapat meningkatkan kinerja karena seorang karyawan dapat menempatkan diri secara tepat kondisi, berani mengambil resiko, mampu menghadapi tantangan dengan penuh tanggung jawab serta mampu berkomunikasi dengan baik terhadap berbagai pihak untuk tetap menjaga produktivitas, kinerja dan menghasilkan individu yang kompeten dalam bidangnya (Sutrisno, 2009). Kemampuan (kompetensi) akan mudah berpengaruh positif dalam pencapaian tingkat kinerja tinggi didukung oleh motivasi kerja yang tinggi Nenny Anggraeni (2011). Dorongan atau motivasi untuk melaksanakan pekerjaan akan muncul apabila pekerjaan yang dikerjakannya dirasakan mempunyai nilai atau berarti oleh para pegawai dalam suatu perusahaan. Hal ini tentu berkaitan dengan pemenuhan kebutuhan masing-masing karyawan agar dapat melaksanakan pekerjaan dengan sebaik-baiknya.

Selain itu, kompensasi merupakan salah satu yang dapat mempengaruhi tinggi rendahnya kinerja tenaga kesehatan. Kompensasi adalah segala sesuatu yang diterima para karyawan sebagai balas jasa untuk kerja mereka (Hani Handoko, 1993). Balas jasa yang diberikan kepada karyawan dapat berbentuk uang (financial) maupun bentuk 
lainnya yang bukan financial, seperti penghargaan dalam jabatan, promosi, dan aktivitas lainnya. Namun Dwi Hastuti (2018), menunjukkan tidak ada pengaruh kompetensi terhadap kinerja kader kesehatan dengan komitmen kerja sebagai variabel intervening. Variable lain yang dapat mempengaruhi kinerja adalah kompensasi. Juliandiny (2016) menunjukkan bahwa Kompensasi mempunyai pengaruh positif terhadap kinerja karyawan dengan tingkat korelasi yang sangat kuat. Hal ini menunjukan bahwa semakin tinggi kompensasi maka semakin tinggi pula kinerja karyawan tersebut. Hal tersebut sejalan dengan Dhermawan (2012) yang menyatakan kompensasi berpengaruh positif dan signifikan terhadap kinerja karyawan. Sebaliknya Herwyndianata (2013) faktor sistem kompensasi tidak berhubungan dengan kinerja perawat.Variabel lainnya yang dapat mempengaruhi kinerja tenaga kesehatan adalah motivasi. Motivasi kerja dapat berfungsi sebagai penggerak bagi seorang karyawan untuk dapat berkerja secara efektif dan terintegrasi untuk mencapai sebuah kepuasan dalam berkerja. Mudayana (2012) menyatakan bahwa adanya pengaruh positif dan signifikan antara motivasi kerja terhadap kinerja karyawan. Eratnya pengaruh motivasi kerja terhadap kinerja karyawan harus memperoleh perhatian khusus bagi pihak manajemen, karena kinerja karyawan yang baik juga dapat menjadi salah satu faktor meningkatnya kinerja rumah sakit karena karyawan menjadi pintu utama dalam pelayanan kesehatan kepada masyarakat. Sebaliknya Inaray (2016), menunjukan bahwa motivasi tidak berpengaruh signifikan terhadap kinerja karyawan. Artinya peningkatan atau penurunan kinerja tidak dipengaruhi motivasi.

\section{METODE}

Penelitian ini merupakan survei analitik. Survei analitik adalah metode penelitian yang mencoba menggali bagaimana dan mengapa fenomena kesehatan itu 
terjadi, kemudian melakukan analisis dinamika korelasi antara fenomena atau antar faktor resiko dengan faktor efek (Notoatmodjo,2010).

Rancangan yang digunakan adalah rancangan cross sectional yaitu suatu penelitian untuk mempelajari dinamika korelasi antara faktor-faktor resiko dengan efek, dengan cara pendekatan, observasi atau pengumpulan data sekaligus pada suatu saat (point time approach)

\section{HASIL PENELITIAN DAN PEMBAHASAN}

\section{Karakteristik Responden}

\section{Berdasarkan Jenis Kelamin}

Karakteristik Responden Berdasarkan Jenis Kelamin dapat diketahui bahwa jumlah responden Wanita Lebih besar yaitu sebanyak 29 orang (58\%) dibandingkan responden Pria yang hanya berjumlah 21 orang (42\%).

\section{Berdasarkan Usia}

Karakteristik Responden Berdasarkan Usia dapat dijelaskan bahwa jumlah responden paling besar berusia 38-47 tahun yaitu sebanyak 25 orang (50\%), sedangkan responden yang berusia $28-37$ tahun berjumlah 24 orang (48\%) dan responden yang berusia 18-27 tahun hanya berjumlah 1 orang ( $2 \%)$.

\section{Berdasarkan Pendidiakn Terakhir}

Karakteristik Responden Berdasarkan Jenis Kelamin dapat diketahui bahwa jumlah responden dengan Pendidikan Terakhir Akademi (D3) lebih besar yaitu sebanyak 30 orang (60\%) dibandingkan responden dengan Pendidikan Terakhir Sarjan (S1) yang hanya berjumlah 20 orang (40\%).

\section{Berdasarkan Masa Kerja}

Karakteristik Responden Berdasarkan Usia dapat diketahui bahwa jumlah responden paling besar yaitu dengan masa kerja 16-20 tahun yaitu sebanyak 14 orang 
(28\%), sedangkan responden dengan masa kerja 5-10 tahun berjumlah 13 orang (26\%), responden dengan masa kerja 11-15 tahun berjumlah 11 orang (22\%), responden dengan masa kerja $>20$ tahun berjumlah 7 orang $(14 \%)$ dan responden dengan masa kerja $<5$ tahun hanya berjumlah 5 orang $(10 \%)$.

\section{Hasil Uji Validitas dan Reliabilitas}

\section{Hasil Uji Validitas}

Validitas diukur dengan menggunakan r. Dengan kriteria, jika r hitung > r table maka butir pertanyaan valid. Dan jika $r$ hitung $>\mathrm{r}$ tabel maka butir pertanyaan tidak valid. ( Sujarweni, 2019 ). Berdasarkan uji validitas semua item pertanyaan kuesioner dinyatakan valid karena semua item pertanyaan memiliki nilai korelasi $>$ dari $\mathrm{r}$ tabel.

\section{Hasil Uji reliabilitas}

Uji Reliabilitas dilakukan dengan tujuan untuk menguji sejauh mana alat pengukur dapat diandalkan atau dipercaya. Dalam Penelitian ini nilai reliabilitas suatu instrumen diterima jika memiliki Alpha Cronbach minimal 0,6. Arikunto dalam Supriyanto dan Machfudz (2010), maka dapat disimpulan bahwa semua item pertanyaan adalah reliabel (dapat diandalkan atau dipercaya).

Berdasarkan hasil uji reliabilitas dalam Penelitian ini nilai reliabilitas semua instrumen diterima atau reliabel karena memiliki Alpha Cronbach minimal dan Cronbach,s Alpha If Item Deleted > dari standar reliabiltas yaitu 0,6.

\section{Hasil Pengujian Asumsi Klasik}

\section{Hasil Uji Normalitas}

Uji normalitas untuk melihat apakah data yang kita miliki berdistribusi normal atau tidak. Uji normalitas dapat dilakukan dengan cara melihat grafik pp-plot, jika pada gambar pp-plot terlihat titik-titik mengikuti dan mendekati garis diagonal, maka dapat disimpulkan data variabel berdistribusi normal. 


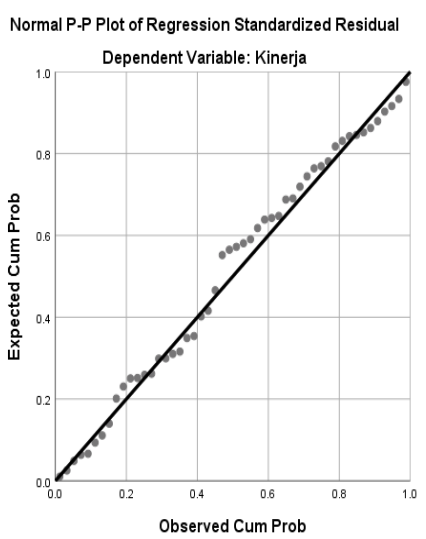

Sumber : Data Primer diolah, 2019

Berdasarkan gambar 1 diatas maka dapat disimpulkan bahwa model regresi berganda dalam penelitian ini tidak ada masalah dalam pengujian normalitas dan layak digunakan dalam penelitian karena titik-titik menyebar di sekitar garis diagonal, serta penyebarannya mengikuti arah garis diagonal, maka grafik tersebut menunjukkan bahwa model regresi layak dipakai karena memenuhi asumsi normalitas.

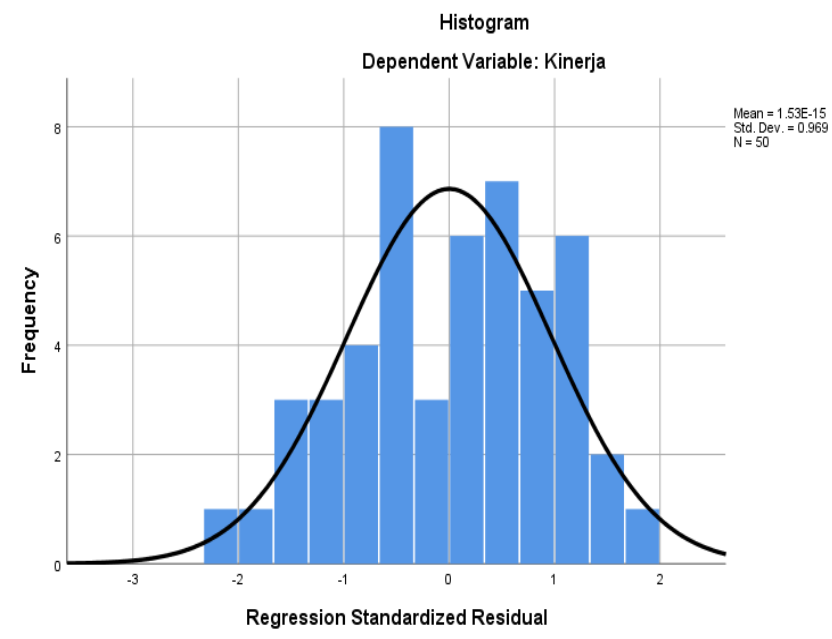

Berdasarkan Gambar 2 diatas maka dapat disimpulkan bahwa model regresi berganda dalam penelitian ini tidak ada masalah dalam pengujian normalitas dan layak digunakan dalam penelitian karena grafik membentuk pola lonceng, maka dapat 
disimpulkan data variabel berdistribusi normal sehingga model regresi layak dipakai karena memenuhi asumsi normalitas.

\section{Hasil Uji Multikolinieritas}

Uji Multikolinieritas adalah keadaan dimana antara dua variabel independen atau lebih terjadi suatu hubungan linier yang sempurna. Model yang baik tidak ada masalah multikolinieritas.

Untuk mendeteksinya melihat nilai Tolerance dan VIF. Semakin kecil nilai tolerance lebih dari 0,1 dan VIF kurang dari 10 maka tidak terjadi multikolinieritas.

Berdasarkan hasil uji Multikolinieritas dapat disimpulakan melalui Variance Inflation factor (VIF) pada hasil output SPSS versi 25.0 model regresi ini bebas dari masalah Multikolinieritas karena masing-masing variabel independen memiliki nilai tolerance lebih dari 0,1 dan VIF kurang dari 10.

\section{Hasil Uji Heterokedastisitas}

Uji Heteroskedastisitas adalah uji untuk mengetahui apakah model regresi terjadi ketidaksamaan variance dari residual satu pengamatan ke pengamatan lainnya.

Caranya adalah dengan mengkorelasi variabel bebas dengan residualnya dapat dilihat pada pola gambar hasil regresi. Jika titik-titik menyebar secara acak dan tidak membentuk pola tertentu yang jelas, serta menyebar di atas maupun di bawah maka tidak terjadi heteroskedastisitas.

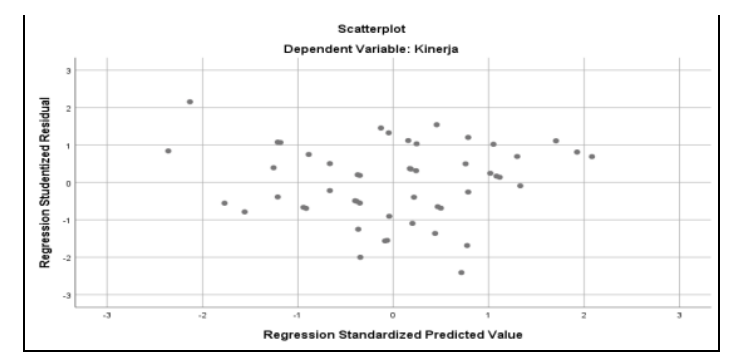

Sumber : Data Primer diolah, 2019

37

Jurnal Komunikasi Bisnis dan Manajemen

Vol.7 No.2 Juli 2020 
Berdasarkan Gambar 3 diatas maka dapat disimpulkan bahwa model regresi berganda dalam penelitian ini terbebas dari heterokesdastisitas dan layak digunakan dalam penelitian karena Titik-titik data menyebar di atas dan di bawah atau di sekitar angka 0, Titik-titik data tidak mengumpul hanya di atas atau di bawah saja dan Penyebaran titik-titik data tidak boleh membentuk pola tertentu.

\section{Hasil Uji Autokorelasi}

Menguji autokorelasi dalam suatu model bertujuan untuk mengetahui ada tidaknya korelasi antara variabel pengganggu pada periode ertentu dengan variabel sebelumnya. Untuk data time series autokorelasi seeing terjadi tapi untuk data yang sampelnya crossection jarang terjadi karena variabel pengganggu satu berbeda dengan yang lainnya.

Berdasarkan hasil uji autokorelasi dapat diketahui nilai d diantara dU dan (4dU) maka dapat disimpulkan bahwa tidak ada autokorelasi.

\section{Analisis Regresi Linier Berganda}

Analisis infersial adalah teknik analisis data menggunakan pendekatan kausalitas atau sebab akibat antara variabel independen dengan variabel dependen. Analisis inferensial ini dipergunakan untuk mengkaji/menganalisis pengaruh beberapa variabel dalam penelitian ini yaitu dengan menggunakan regresi linear berganda.

Tabel 9 Regresi Linier Berganda, Koefisien Determinasi dan Hipotesis

\begin{tabular}{|c|c|c|c|c|c|}
\hline \multicolumn{6}{|c|}{ Coefficients ${ }^{a}$} \\
\hline \multirow[t]{2}{*}{ Model } & \multicolumn{2}{|c|}{$\begin{array}{l}\text { Unstandardized } \\
\text { Coefficients }\end{array}$} & $\begin{array}{l}\text { Standardized } \\
\text { Coefficients }\end{array}$ & $\mathrm{t}$ & Sig. \\
\hline & B & Std.Error & Beta & & \\
\hline (Constant) & 2.228 & 4.893 & & .455 & .651 \\
\hline KOMPETENSI & .394 & .130 & .384 & 3.044 & .004 \\
\hline
\end{tabular}




\begin{tabular}{|l|l|l|l|l|l|l|}
\hline & KOMPENSASI & .076 & .153 & .065 & .498 & .621 \\
\cline { 2 - 7 } & MOTIVASI & .535 & .156 & .419 & 3.432 & .001 \\
\hline
\end{tabular}

a. Dependent Variable: KINERJA

$\begin{array}{ll}\mathrm{R} & =0,602 \\ \mathrm{~N} & =50\end{array}$

R Square $=0,362 \quad$ F Hitung $=8,711$

Adjusted R Square $=0,321 \quad$ Sig $F=0,000$

Sumber : Lampiran SPSS diolah, 2019

Pada Tabel 9 dapat dilihat $\mathrm{R}$ sebesar 0,602 menunjukkan bahwa korelasi atau hubungan antara Kompetensi, Kompensasi, dan Motivasi terhadap Kinerja Tenaga Kesehatan di Rumah Sakit Umum Daerah dr. H. Moch. Ansari Saleh Banjarmasin adalah korelasi kuat yaitu berkisar antara 0,60- 0,799.

Berdasarkan Tabel 9 diperoleh persamaan regresi sebagai berikut: $\mathrm{Y}=2,228+0,394 \mathrm{X} 1+0,076 \mathrm{X} 2+0,535 \mathrm{X} 3+\mathrm{e}$

Hal ini menunjukkan ketiga variabel bebas yaitu Kompetensi dengan nilai Koefisien Beta 0,394, Kompensasi dengan Koefisien Beta 0,076, dan Motivasi Kompetensi dengan nilai Koefisien Beta 0,535, memiliki pengaruh positif terhadap variaber terikatnya yaitu kinerja.

\section{Analisis Koefisien Determinasi( $\left.\mathbf{R}^{2}\right)$}

Bersarkan Tabel 9 dapat dilihat perhitungan koefisien determinasi total $\left(\mathrm{R}^{2}\right)$ atau angka R Square dilakukan untuk mengetahui besarnya kontribusi (pengaruh) secara keseluruhan dari variabel X1, X2 dan X3 terhadap Y secara persentase. Jika R Square yang diperoleh dari hasil perhitungan mendekati 1 (satu) maka semakin kuat model regresi dapat menerangkan variabel dependennya. Hasil análisis regresi diperoleh nilai R Square 0,362 yang artinya pengaruh secara simultan variabel bebas (Kompetensi, Kompensasi, dan Motivasi) terhadap variabel terikatnya (Kinerja) Tenaga Kesehatan di 
Rumah Sakit Umum Daerah dr. H. Moch. Ansari Saleh Banjarmasin adalah 36,2\% sedangkan sisanya 63,8\% dijelaskan oleh sebab lain diluar dari penelitian ini.

\section{Hasil Pengujian Hipotesis}

Pengujian pengaruh variabel bebas terhadap variabel terikat secara parsial dilakukan dengan mencari koefisien regresi ( $\beta \mathrm{i})$ yang paling besar, selanjutnya dilakukan pengujian secara parsial melalui uji t.

Pada taraf signifikansi (taraf kepercayaan) $5 \%$ dan rumus derajat bebas/degre of freedom, $\mathrm{df}=\mathrm{n}-\mathrm{K}=50-4=46$ maka didapat nilai $\mathrm{t}$ tabel 2,013. Jika nilai $\mathrm{t}$ hitung lebih besar dari pada nilai $t$ tabel maka pengaruhnya signifikan.

Bersarkan Tabel 9 dapat dilihat pengujian secara parsial (uji t) digunakan untuk membuktikan hipotesis 1, hipotesis 2 dan hipotesis 3 yaitu sebagai berikut :

1. Pengaruh variabel Kompetensi (X1) terhadap Kinerja Tenaga Kesehatan di Rumah Sakit Umum Daerah dr. H. Moch. Ansari Saleh Banjarmasin adalah sebagai berikut: Nilai t hitung variabel Kompetensi adalah sebesar 3,044, hasil ini lebih besar dibandingkan $t$ tabel sebesar 2,013 dengan demikian variabel Kompetensi secara parsial berpengaruh positif signifikan terhadap Kinerja Tenaga Kesehatan di Rumah Sakit Umum Daerah dr. H. Moch. Ansari Saleh Banjarmasin dengan probabilitas tingkat kesalahan variabel sebesar 0,004 (lebih kecil dari 0,05). Dengan demikian hipótesis (H1) yang menyatakan bahwa Kompetensi secara parsial berpengaruh positif dan signifikan terhadap Kinerja Tenaga Kesehatan di Rumah Sakit Umum Daerah dr. H. Moch. Ansari Saleh Banjarmasin dinyatakan diterima.

2. Pengaruh variabel Kompensasi (X2) terhadap Kinerja Tenaga Kesehatan di Rumah Sakit Umum Daerah dr. H. Moch. Ansari Saleh Banjarmasin adalah sebagai berikut: Nilai t hitung variabel Kompensasi adalah sebesar 0,498, hasil ini lebih kecil dibandingkan $\mathrm{t}$ tabel sebesar 2,013 dengan demikian variabel Kompensasi secara parsial berpengaruh positif tidak signifikan terhadap Kinerja Tenaga Kesehatan di 
Rumah Sakit Umum Daerah dr. H. Moch. Ansari Saleh Banjarmasin dengan probabilitas tingkat kesalahan variabel sebesar 0,621 (lebih besar dari 0,05). Dengan demikian hipótesis (H2) yang menyatakan bahwa Kompensasi secara parsial berpengaruh positif dan signifikan terhadap Kinerja Tenaga Kesehatan di Rumah Sakit Umum Daerah dr. H. Moch. Ansari Saleh Banjarmasin dinyatakan ditolak.

3. Pengaruh variabel Motivasi (X3) terhadap Kinerja Tenaga Kesehatan di Rumah Sakit Umum Daerah dr. H. Moch. Ansari Saleh Banjarmasin adalah sebagai berikut: Nilai t hitung variabel Motivasi adalah sebesar 3,342, hasil ini lebih besar dibandingkan $\mathrm{t}$ tabel sebesar 2,013 dengan demikian variabel Kompetensi secara parsial berpengaruh positif signifikan terhadap Kinerja Tenaga Kesehatan di Rumah Sakit Umum Daerah dr. H. Moch. Ansari Saleh Banjarmasin dengan probabilitas tingkat kesalahan variabel sebesar 0,001 (lebih kecil dari 0,05). Dengan demikian hipótesis (H3) yang menyatakan bahwa Motivasi secara parsial berpengaruh positif dan signifikan terhadap Kinerja Tenaga Kesehatan di Rumah Sakit Umum Daerah dr. H. Moch. Ansari Saleh Banjarmasin dinyatakan diterima.

\section{Hasil Pengujian Hipotesis Secara Simultan}

Pengujian secara bersama-sama (simultan) uji F digunakan untuk membuktikan hipotesis (H4) variabel Kompetensi, Kompensasi, dan Motivasi secara simultan mempengaruhi Kinerja Tenaga Kesehatan di Rumah Sakit Umum Daerah dr. H. Moch. Ansari Saleh Banjarmasin.

Nilai F tabel menggunakan tingkat signifikasi (taraf kepercayaan) $5 \%$ dan rumus derajat bebas/degre of freedom, df $1=\mathrm{K}-1=4-1=3$ dan df $2=\mathrm{n}-\mathrm{K}=50-4=46$ maka didapat nilai $F_{\text {tabel }}$ sebesar 2,81.

Hal ini terbukti dari nilai F hitung yang dapat dilihat berdasarkan Tabel 9, nilai F hitung $(8,711)$ lebih besar dari F tabel $(2,81)$ dan nilai signifikansi 0,000 lebih kecil dari 0,05 sehingga hipótesis (H4) dapat diterima. 
Tingkat kepercayaan yang diambil pada penelitian ini adalah 95\% dengan signifikansi 5\% penjelasan tersebut sesuai dengan ketentuan jika F hitung lebih besar dari F tabel, maka variabel bebas secara simultan memiliki pengaruh yang signifikan terhadap kinerja Tenaga Kesehatan di Rumah Sakit Umum Daerah dr. H. Moch. Ansari Saleh Banjarmasin. Berdasarkan uraian diatas dapat disimpulkan hipótesis (H4) yang menyatakan bahwa variabel Kompetensi, Kompensasi, dan Motivasi secara simultan berpengaruh positif dan signifikan terhadap Kinerja Tenaga Kesehatan di Rumah Sakit Umum Daerah dr. H. Moch. Ansari Saleh Banjarmasin terbukti.

Berdasarkan hasil analisis juga dapat disimpulkan bahwa variabel Motivasi adalah variabel yang dominan berpengaruh positif dan signifikan terhadap kinerja Tenaga Kesehatan di Rumah Sakit Umum Daerah dr. H. Moch. Ansari Saleh Banjarmasin dengan nilai kolerasi parsial yang paling tinggi yaitu 0,440 dibandingkan korelasi parsial Kompetensi $(0,413)$ dan Kompensasi $(0,304)$.

\section{KESIMPULAN}

Berdasarkan hasil penelitian, pembahasan, dan kesimpulan, maka saran yang dapat diberikan adalah sebagai berikut:

1. Bagi pihak Pimpinan dan Tenaga Kesehatan Rumah Sakit Umum Daerah dr. H. Moch Ansari Saleh Banjarmasin diharapkan dapat lebih meningkatkan Kompetensi Tenaga Kesehatan misalnya dengan rutin mengadakan seminar maupun pelatihan.

2. Dalam hal kompensasi pimpinan Rumah Sakit bisa memberikan perhatian lebih terutama mengenai hal yang menyangkut tunjangan dan uang jasa BPJS.

3. Dalam hal Motivasi pimpinan Rumah Sakit diharapkan dapat meningkatkan motivasi kerja dengan memberikan kejelasan tentang tujuan visi dan misi Rumah Sakit dengan penjelasan secara spesifik dan memberikan solusi tentang pencapaian target. Selanjutnya, dengan adanya penghargaan yang diberikan terhadap 
karyawan dalam hal ini Tenaga Kesehatan akan memacu para karyawan untuk mencapai tingkat kinerja yang lebih tinggi. Umpan balik seperti komisi atau bonus mungkin dapat ditingkatkan agar para karyawan lebih bersemangat dalam mencapai target. Dan bagi Tenaga Kesehatan diharapkan dapat menentukan tujuan kerjanya sendiri dan peduli terhadap pekerjaannya. Hal ini dapat meningkatkan motivasi dalam dirinya. Dan perlu diperhatikan bagi Tenaga Kesehatan untuk meningkatkan kinerja sehingga visi misi dan tujuan Rumah Sakit dapat dicapai dengan efektif dan efisien agar dapat memaksimalkan pencapaian Rumah Sakit tersebut.

\section{DAFTAR PUSTAKA}

Notoatmodjo, S, 2010. Ilmu Perilaku Kesehatan Edisi Revisi. Jakarta: PT. Rineka Cipta Inaray, J. C., Nelwan, O.S., \& Lengkong, V. P. K. (2016). Pengaruh Kepemimpinan dan Motivasi Kerja Terhadap Kinerja Karyawan Pada PT. Amanah Finance di Manado.Jurnal Berkala Ilmiah Efisiensi,16 (2), 458-470.

Undang-undang Republik Indonesia Nomor 36 Tahun 2014 tentang Tenaga Kesehatan.

Wibowo. 2009. Manajemen Kinerja. Jakarta: PT. Raja Grafindo.

Sutrisno, Edi. 2009. Manajemen Sumber Daya Manusia Edisi pertama. Jakarta: Kencana Prenada Media Group.

Hastuti, Dwi. 2018. Pengaruh Motivasi, Kompetensi dan Kepuasan Terhadap Kinerja Kader Kesehatan Dengan Komitmen Kerja Sebagai Variabel Intervening. Jurnal Magisma Vol.6 No.1 - Tahun 2018.

Anggareni, N. 2011. Pengaruh Kemampuan dan Motivasi Terhadap Kinerja Pegawai Pada Sekolah Tinggi Seni Indonesia (STSI) Bandung. Manajemen Produksi Jurusan Karawitan. Sekolah Tinggi Seni Indonesia (STSI) Bandung.

Handoko, Hani 1993. Dasar-dasarManajemen Produksi dan Operasi, cetakan ketujuh. Yogyakarta: BPFE

Herwyndianata. 2013. Analisis Faktor yang Berhubungan dengan Kinerja Perawat dalam Penerapan Standar Asuhan Keperawatan di Unit rawat Inap RSU Anutapura Palu. Skripsi Fakultas Kesehatan Masyarakat. Universitas Hasanuddin Makassar. 
